\title{
Cooperative advertising in competing supply chains and the long-term effects of retail advertising
}

\author{
Salma Karray $^{\mathrm{a} *}$, Guiomar Martín-Herrán ${ }^{\mathrm{b} \dagger}$, and Simon-Pierre Siguéc ${ }^{\ddagger}$ \\ a University of Ontario Institute of Technology. Canada. Email: salma.karray@uoit.ca; \\ bIMUVA, Universidad de Valladolid, Spain. Avda. Valle Esgueva, 6. 47011-Valladolid. Spain. \\ Phone: +34 983 423330. Email: guiomar@eco.uva.es; and c Athabasca University, Canada. \\ Email: simon.sigue@fb.athabascau.ca
}

\section{ARTICLE HISTORY}

Compiled April 14, 2021

\begin{abstract}
The profitability of cooperative advertising (CA) programs is analyzed in a supply chain where competing manufacturers sell their products through competing retailers. We study a two-period game-theoretic model that accounts for positive and negative long-term effects of retail advertising on consumer preferences. We obtain closed-form equilibria in two particular cases where either the stores or the products are perfectly differentiated. For the general case where both products and stores can be substitutable, we develop a numerical algorithm to find the equilibrium. We compare the equilibria obtained in games where CA is offered and where it is not. The results show that the second-period effects of first-period retail advertising and the levels of substitutability between products and between retailers all play a key role in assessing the profitability of CA programs. CA only benefits manufacturers when store and product competition are both low, or when retailers are highly differentiated. However, in most cases, retailers do not find such programs profitable except when product substitutability levels are high while store competition is low. Finally, CA can only be win-win arrangements for manufacturers and retailers when the level of store differentiation is very high, the products are moderately substitutable, and first-period retail advertising has a substantial positive impact on second-period sales. The manufacturers' cooperative advertising support rates increase with the second-period effects of retail advertising.
\end{abstract}

\section{KEYWORDS}

OR in Marketing; Cooperative Advertising; Competition; Supply Chain Management; Game Theory;

\section{Introduction}

Cooperative advertising is an arrangement by which a manufacturer commits to reimburse the retailer a share of its local advertising expenses for the manufacturer's product. Such programs mainly aim at providing incentives to retailers to further fea-

\footnotetext{
* The author is grateful to the Natural Sciences and Engineering Research Council of Canada (NSERC) for their financial supports (RGPIN-2020-05156).

$\dagger$ Corresponding author. The author gratefully acknowledges financial support from the Spanish Spanish MINECO (AEI) under project ECO2017-82227-P and from Junta de Castilla y León under projects VA105G18 and VA169P20 co-financed by FEDER funds (EU).

$\ddagger$ The author gratefully acknowledges financial support from Athabasca University under an ARF grant.
} 
ture the manufacturer's product in their promotional activities including store flyers, displays, direct mail, advertising in local media, and promotional giveaways (Borrell Associates, 2015). Manufacturers are believed to benefit from cooperative advertising in at least three different ways. First, retailers have a deeper knowledge of local markets, which allows them to better design, target, and schedule their promotional activities. Second, the costs of local media, such as newsletters and radio, used by most retailers are generally lower than the national media commonly used by manufacturers. Finally, retailers are known to favour promotional activities that stimulate immediate sales, which can benefit the manufacturers' revenues.

Given these benefits, cooperative advertising programs are widely used in many industries. Estimates in the U.S. indicate that manufacturers pay around $\$ 36$ billion per year to retailers as part of cooperative advertising arrangements (Borrell Associates, 2015). However, not all manufacturers offer cooperative advertising programs to their retailers. Those who do, very often impose restrictive conditions to exclude certain types of retail advertising that may not serve their interests. In fact, while there is an agreement about the positive short-term (ST) impact of retail advertising, its long-term (LT) impact on sales and consumer preferences remains contentious. The marketing literature suggests that some retail advertising activities can negatively impact brand preference in the long run (Atman et al., 2010; Buil et al., 2013; DelVecchio et al., 2006; Herrington and Dempsey, 2005; Yi and Yoo, 2011). This has led manufacturers such as Toyota, Yamaha, Mitsubishi, Honda and many others to proscribe specific retail advertising that features prices below invoice, or that does not obey certain specifications for brand advertising (Barkholz, 2015; Yamaha co-op advertising guidelines, 2016; TastyAd, 2018).

In the theoretical literature about cooperative advertising, most works have overlooked the long-term effects of retail advertising and have used static game modelling in their analyses (e.g., Bergen and John, 1997; Gou et al., 2020; Karray, 2015; Liu et al, 2014; Xie and Ai, 2006; Yan, 2010). Others have assumed that retail advertising only positively affects sales over time (e.g., He et al., 2011; Chutani and Sethi, 2018; Jørgensen et al., 2000, 2001; Sigué and Chintagunta, 2009; Zhang et al., 2013), while others have also modelled its negative LT impacts (Jørgensen et al., 2003; Huang et al., 2018; Karray et al., 2017a). A few scholars, however, have taken a broader and more integrative view, and considered that retail advertising may have no LT effect or produce either positive or negative LT effects depending on the nature of the promotional activities (Martín-Herrán and Sigué, 2017a, 2017b; Martín-Herrán et al., 2010; Sigué and Karray, 2007). In this specific literature, which uses two-period modelling, first-period advertising is considered to have LT effects when it affects second-period sales.

Therefore, the challenge for both supply chain managers and scholars has been to develop a deeper understanding of the various long-term effects of retail advertising on the profitability of cooperative advertising programs for manufacturers and retailers, considering various channel structures. In fact, there is increasing evidence that manufacturers cannot afford to ignore the LT effects of retail advertising if they want to develop and implement mutually profitable cooperative advertising programs. For instance, in a bilateral monopoly context, Martín-Herrán and Sigué (2017a) recently demonstrated that the nature (positive or negative) of the LT effects of retail advertising influences channel members' decisions and profits. More importantly, contrary to most differential game models in the literature, which prescribe stationary advertising strategies (e.g., He et al., 2011; Jørgensen et al., 2000, 2001; Sigué and Chintagunta, 2009; Zhang et al., 2013), Martin-Herran and Sigué (2017a) found that due to the 
LT effects of retail advertising, manufacturers may find it optimal to not continuously provide advertising support to retailers. This is supported by observations from the practice of cooperative advertising programs, as most manufacturers announce their cooperative advertising programs periodically and with specific guidelines. For example, a company such as Mitsubishi Motors often offers periodic cooperative advertising programs of three to four months duration in North America to support retail advertising that exclusively promotes its product features and value. Retail advertising that uses "distressed language" such as blowout, liquidation, sell off, everything has to go, won't be undersold, supplier pricing, special pricing, and special discount to sell vehicles does not meet the requirements of these programs. This type of retail advertising is believed to damage the integrity of the Mitsubishi brand in the long run and cannot be supported (Mitsubishi Motors, 2012, 2015). Also, Yamaha offers annual cooperative advertising programs that prohibit any retail advertising that may damage the reputation of its motorcycles (Yamaha co-op advertising guidelines, 2016).

Our main contributions are as follows. First, our model captures competition between retailers as well as between manufacturers. Second, we account for positive as well as negative effects of retail advertising over two periods. Third, we solve for both advertising and pricing decisions in the supply chain. Finally, while many works in the literature rely on aggregate demand models, we use a demand function that is derived from maximization of a consumer utility. Our research questions, then, are:

(1) In a supply chain with both retail and product competition, should manufacturers and retailers engage in cooperative advertising programs, given the potential LT effects of retail advertising? How do these results change when competition is absent at the retail or product level?

(2) How do the LT effects of retail advertising and competition levels impact the manufacturers' cooperative advertising support rates?

To answer these questions, we develop a two-period game-theoretic model that considers two competing retailers, each selling the products of two competing manufacturers. We differentiate between product competition and store competition, and model the LT effects of retail advertising by considering that the retailers' first-period advertising activities can impact second-period consumer utility either positively or negatively. We use the Stackelberg solution concept to solve two games (i.e., with and without cooperative advertising) and obtain subgame-perfect equilibrium solutions either analytically or numerically. We also analyse two simplified versions of the model by considering special cases of perfectly differentiated products and stores. Comparisons of profits across games show that the profitability of cooperative advertising for manufacturers and retailers depends on the nature and magnitude of the LT effects of retail advertising and the substitutability of the two products and stores. Also, conditions under which a cooperative advertising program is a win-win coordination mechanism for manufacturers and retailers are identified. Contrary to previous research that did not model retail competition, our findings indicate that retail advertising that does not affect or hurt the brand in the LT should not be supported.

The rest of the paper is organised as follows. First, we present an overview of the relevant literature on cooperative advertising in competitive channels. Second, we describe the model and games and discuss our assumptions. Third, we describe the methodology used to derive the equilibrium solutions for each game under the general and the simplified model formulations and compare equilibrium outcomes. Finally, we conclude and discuss the research and managerial implications. 


\section{Literature review}

The theoretical literature on cooperative advertising programs in supply chains is extensive. Aust and Buscher (2014a) and Jørgensen and Zaccour (2014) offered excellent comprehensive reviews of works in this field. We focus on theoretical studies that have modelled competition either between manufacturers, retailers, or both. Table 1 summarizes the literature relevant to this research and highlights our distinctive contributions.

The theoretical literature that has analysed the profitability of cooperative advertising programs in competing supply chains can be categorized into static and dynamic models. Static models consider that advertising effects are limited to current sales and have no effect on subsequent-period sales. In this research stream, Bergen and John (1997) used a Hotelling model and showed that cooperative advertising programs can benefit a single manufacturer selling through multiple retailers. Assuming a similar supply chain structure, Aust and Buscher (2014b) relied on a utility-based demand to assess whether retailers should cooperate or act independently when the manufacturer offers cooperative advertising support. Karray and Amin (2015) used an aggregate demand function and found that, while cooperative advertising is a profit-enhancing mechanism for the manufacturer, it may hurt the retailers' profitability, especially when demand is less sensitive to retail prices and stores are highly substitutable.

A few works proposed static models considering a supply chain where multiple manufacturers are selling to competing retailers (Karray and Zaccour, 2007; Karray, 2015; Karray et al., 2017b; Liu et al., 2014). As we do in this research, Karray and Zaccour (2007) considered two manufacturers selling their products through two competing retailers. In this configuration, each retailer carries the products of the two manufacturers. Their paper disregarded retail prices and focused on advertising competition between both the manufacturers and retailers. These authors found that the profitability of cooperative advertising for channel members is determined by the levels of store and product substitutability/ differentiation. In particular, cooperative advertising programs have the characteristics of a prisoner's dilemma for manufacturers when their products are highly substitutable, while they only benefit the retailers when their stores are sufficiently differentiated. Cooperative advertising support rates increase as the level of substitutability between products and stores respectively increases and decreases.

Considering two competing manufacturers and retailers, Liu et al. (2014) focused on a set-up where each retailer carries only the product of one manufacturer. They solved for equilibrium prices and advertising efforts assuming exogenous support rates and found that while manufacturers can benefit from cooperative advertising, retailers do not. This is because cooperative advertising increases channel prices, which leads to a contraction of consumer demand. Using a similar supply chain structure, Karray (2015) studied a cooperative advertising problem but did not assess its profitability. Finally, Karray et al. (2017b) considered various channel structures where two competing manufacturers can potentially sell their products through two competing exclusive retailers and each supply chain member makes both pricing and advertising decisions. The manufacturers also have the possibility of adopting integrated channels to sell directly to consumers. The impact of vertical and horizontal externalities on the effectiveness of cooperative advertising programs were examined. Among others, they found that the profitability of cooperative advertising depends on the levels of price and advertising competition.

The literature about cooperative advertising in competitive channels that models 


\begin{tabular}{|c|c|c|c|c|}
\hline & $\begin{array}{l}\text { Strategic } \\
\text { pricing }\end{array}$ & $\begin{array}{l}\text { Retailers carry } \\
\text { multiple products }\end{array}$ & $\begin{array}{l}\text { Positive LT retail } \\
\text { advertising effects }\end{array}$ & $\begin{array}{l}\text { Negative LT retail } \\
\text { advertising effects }\end{array}$ \\
\hline \multicolumn{5}{|l|}{1 manufacturer, 2 retailers } \\
\hline Sigué and Chintagunta (2009) & & & $\mathrm{x}$ & \\
\hline He et al. (2011) & & & $\mathrm{x}$ & \\
\hline Chutani and Sethi (2012) & $\mathrm{x}$ & & $\mathrm{x}$ & \\
\hline Chutani and Sethi (2014) & & & $\mathrm{x}$ & \\
\hline Aust and Buscher (2014b) & $\mathrm{x}$ & & & \\
\hline Karray and Amin (2015) & $\mathrm{x}$ & & & \\
\hline Huang et al. (2018) & & & $\mathrm{x}$ & $\mathrm{x}$ \\
\hline \multicolumn{5}{|l|}{2 manufacturers, 1 retailer } \\
\hline Karray et al. (2017a) & $\mathrm{x}$ & & $\mathrm{x}$ & $\mathrm{x}$ \\
\hline \multicolumn{5}{|l|}{2 manufacturers, 2 retailers } \\
\hline Karray and Zaccour (2007) & & $\mathrm{x}$ & & \\
\hline Liu et al. (2014) & $\mathrm{x}$ & & & \\
\hline Karray (2015) & $\mathrm{x}$ & & & \\
\hline Karray et al. (2017b) & $\mathrm{x}$ & & & \\
\hline Chutani and Sethi (2018) & & $\mathrm{x}$ & $\mathrm{x}$ & \\
\hline This paper & $\mathrm{x}$ & $\mathrm{x}$ & $\mathrm{x}$ & $\mathrm{x}$ \\
\hline
\end{tabular}

advertising LT effects has most often used differential game models, which assume that advertising is done continuously and produces carryover effects that depreciate over time. As a result, manufacturers also continuously support retailers' advertising over time. Most of these works studied a channel configuration in which a manufacturer deals with competing retailers (e.g., Chutani and Sethi, 2012, 2014, 2018; He et al., 2011; Huang et al., 2018; Sigué and Chintagunta, 2009). In particular, Huang et al. (2018) considered that competing retailers' local advertising activities can either benefit or harm the brand image of the manufacturer's product in a set-up where prices are fixed. They showed that cooperative advertising can be beneficial when advertising effects are not too harmful or when the brand's initial image is low. This result is in line with Jørgensen et al. (2003) who considered a similar problem but did not account for competition at any level of the supply chain.

Competition between manufacturers is disregarded in this research stream with the exception of Chutani and Sethi (2018) who investigated cooperative advertising arrangements in a supply chain formed by multiple manufacturers who are dealing with multiple retailers. Their model focused exclusively on advertising and assumed exogenous prices. Their findings indicated that the profitability of cooperative advertising for both manufacturers and retailers depends on, among others, the level of competition. When symmetric channel partners are considered, manufacturers do not offer cooperative advertising programs, as these damage their profits to the benefit of retailers. In addition, manufacturers provide large (small) cooperative advertising support to retailers when the level of substitutability between products (stores) is high. Finally, the differential game literature about cooperative advertising in competing supply chains has relied on aggregate models. Also, as we can see in Table 1, with the exception of Huang et al. (2018), it has not accounted for possible harmful LT advertising effects on brand goodwill or sales.

Different from these works, Karray et al. (2017a) used a two-period model to study the effectiveness of cooperative advertising in a supply chain with a manufacturer, but no retail competition. They accounted for positive and negative LT retail advertising effects and found that the profitability of cooperative advertising for the manufacturers and the retailer depends on the nature and magnitude of the advertising LT effects and the level of product substitutability. Karray et al.'s (2017a) findings extended those in Huang et al. (2018) and Jørgensen et al. (2003) who also modelled the harmful long- 
term impact of advertising. They showed that it is not in the interest of manufacturers to offer cooperative advertising programs when their products are fairly substitutable or when the advertising effect is highly negative.

As we see in Table 1, this study contributes to the existing literature about cooperative advertising programs in competitive supply chains as follows. First, our model captures positive as well as negative effects of retail advertising over two periods. Second, it differentiates between retail and manufacturer competition. Third, we solve for both advertising and pricing decisions in the supply chain. Finally, while many works in the literature relied on aggregate demand models, we use a demand function that is derived from maximization of consumer utility. This allows the model to better capture and interpret the effect of the firms' strategies on consumer utility and sales.

\section{Models}

Consider a supply chain formed by two competing manufacturers selling their products to two competing retailers. The manufacturers and retailers are strategic players, making their decisions over a two-period planning horizon. They play a sequential game à la Stackelberg where manufacturers are leaders and retailers are followers.

The decisions made by the players are described next. In each period $j$, each retailer $k$ sets his retail price, $p_{i j k}$, for the manufacturer $i$ 's product $(i, j, k \in\{1,2\})$ and the latter sets her wholesale price, $w_{i j}$. In period 1 , each retailer also decides on his local advertising effort, $a_{i k}$, which consists of a variety of activities, including ads in local media, direct mail, in-store displays, and store catalogues that stimulate local sales. When manufacturers offer cooperative advertising, they also set cooperative advertising support rates, $s_{i}$, in the first period of the game. All notations considered in the model are included in Table 2.

To focus on the long-term effects of local retail advertising, we assume that retailers and manufacturers make their advertising decisions in the first period of the game (Karray et al., 2017a; Martín-Herrán and Sigué, 2017b). This assumption is based on the observation that manufacturers usually commit to their cooperative advertising rates for a long period of time (e.g., over a few months, up to one or two years). The retailers' local advertising decisions also involve commitments with advertising agencies to design advertising campaigns in TV, radio, and other local media or to create advertising materials such as catalogues, billboards, and in-store displays (Gou et al., 2020). These commitments and other considerations explain why many firms adopt pulsing strategies where advertising is used for a certain time duration followed by periods of non-advertising activity (Freimer and Horsky, 2012; Martín-Herrán and Sigué, 2017b).

We also assume that each manufacturer offers the same cooperative advertising support rate and wholesale price to both retailers. This is to abide with legal antidiscriminatory requirements in countries such as Canada and the U.S., such as the Robinson-Patman Act of 1936. This legislation proscribes the granting of any pricerelated advantage to a purchaser that is not made available to its competitors.

\subsection{Games and sequence of play}

To investigate the effects of cooperative advertising in a channel with competing manufacturers and retailers, we solve the following two games. The No Cooperative Advertising (NCA) game refers to the situation where manufacturers provide no advertising 


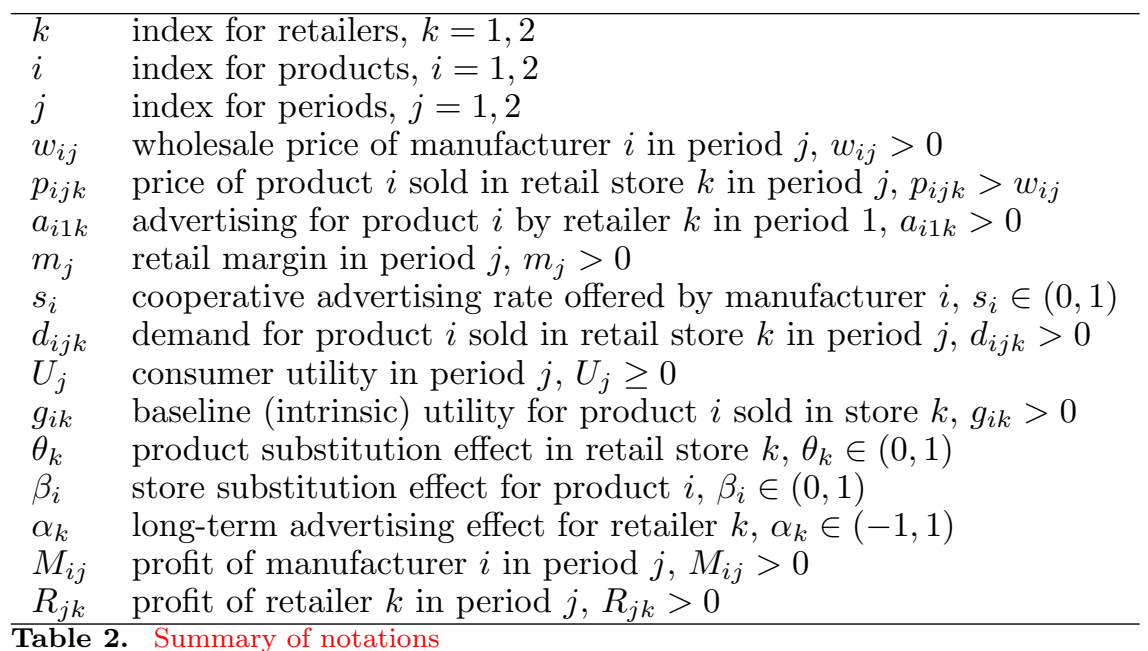

support to retailers $\left(s_{i}=0, i \in\{1,2\}\right)$, while the Cooperative Advertising (CA) game is played when each manufacturer $i$ proposes a cooperative advertising support rate, $s_{i} \neq 0(i \in\{1,2\})$, to retailers. These games represent what-if scenarios that allow us to study the effects of cooperative advertising programs. Specifically, comparison of equilibrium outputs obtained in the NCA and CA games helps to assess the impact of cooperative advertising programs on the supply chain members' profitability as well as on strategic pricing and advertising decisions.

Whether or not the manufacturers offer cooperative advertising programs, we consider that the manufacturers and retailers play a Stackelberg game where the manufacturers are leaders and the retailers are followers. At each stage of each game, the manufacturers or retailers play Nash.

The sequence of play for the two games can be formally described as follows, for $i, k=1,2$.

- NCA game: This game is played in four stages. In the first stage, the manufacturers play Nash and simultaneously decide on their first-period wholesale prices $\left(w_{i 1}\right)$. In the second stage, the retailers also play Nash. They simultaneously react to the manufacturers' wholesale price announcement and set their first-period pricing and local advertising decisions. In the third stage of the game, the manufacturers play Nash and simultaneously choose their second-period wholesale prices $\left(w_{i 2}\right)$, knowing all announced first-period decisions $\left(w_{i 1}, p_{i 1 k}\right.$ and $\left.a_{i 1 k}\right)$. Finally, the retailers simultaneously set their second-period prices $\left(p_{i 2 k}\right)$ knowing all announced decisions in the previous stages of the game $\left(w_{i 1}, p_{i 1 k}, a_{i 1 k}\right.$, and $\left.w_{i 2}\right)$.

- CA game: This game is also played in four stages. First, the manufacturers play Nash and announce their respective first-period wholesale prices $\left(w_{i 1}\right)$ and their cooperative advertising rates $\left(s_{i}\right)$. Second, the retailers play Nash and simultaneously set their first-period prices $\left(p_{i 1 k}\right)$ and local advertising decisions $\left(a_{i 1 k}\right)$, knowing the manufacturers' first-period wholesale prices and cooperative advertising rates. Third, the manufacturers play Nash and choose their secondperiod wholesale prices $\left(w_{i 2}\right)$, knowing their first-period wholesale prices and cooperative advertising rates as well as the retailers' first-period prices and local advertising decisions. Fourth and finally, the retailers play Nash and simultaneously decide on their second-period prices $\left(p_{i 2 k}\right)$, knowing all previously an- 
nounced decisions. This sequence of decision making is based on the observation that many manufacturers announce their cooperative program terms and keep them unchanged for long periods that can span a year or two (see examples in the Introduction section). Also, retailers are generally aware of manufacturers' cooperative advertising offers when they make their advertising and pricing decisions.

\subsection{Demand functions}

To obtain the demand functions, $d_{i j k}$, of product $i$ at the store of retailer $k$ in period $j$, we adapt the quadratic consumer utility function in Spence (1976) which has been widely used in economics and management science (Choi and Coughlan, 2006; Häckner, 2000; Singh and Vives, 1984). The utility formulation in period $j$ is given by

$$
\begin{aligned}
U_{j} & =\sum_{k=1,2} \sum_{i=1,2}\left(\left[g+f_{j}\left(a_{i j k}\right)\right] d_{i j k}-d_{i j k}^{2} / 2\right)-\sum_{k=1,2}\left(\theta d_{1 j k} d_{2 j k}\right)-\sum_{i=1,2}\left(\beta d_{i j 1} d_{i j 2}\right) \\
& -\sum_{k=1,2} \sum_{i=1,2}\left(p_{i j k} d_{i j k}\right),
\end{aligned}
$$

where $f_{1}\left(a_{i 1 k}\right)=a_{i j k}$ and $f_{2}\left(a_{i 1 k}\right)=\alpha a_{i 1 k}$.

This linear quadratic utility formulation exhibits the following classical economic properties: (i) the representative consumer's utility of owning a product decreases as the consumption of the substitute product increases; (ii) the marginal utility for a product diminishes as the consumption of the product increases; and (iii) the value of using multiple substitutable products is less than the sum of the separate values of using each product on its own (Samuelson, 1974). The characteristics of the demand functions provided are desirable in most substitutable product contexts in the real world, as they ensure, among others, that the consumption of one product comes at the expense of the other, and that consumers can reach a level of saturation, where there is no longer any interest in acquiring additional units of either product.

The parameter $g$ is positive and represents the baseline (intrinsic) utility when retailers do not advertise and products are perfectly differentiated. This formulation assumes that advertising for a product affects its baseline value through the advertising function, $f_{j}\left(a_{i j k}\right)$ (as in Liu et al. (2014) and in Karray et al. (2017a)). In the first period, it consists of the baseline utility $(g)$ increased by the positive advertising effects undertaken for the product in the first period $\left(a_{i 1 k}\right)$. In the second period, the expanded baseline utility consists of $g$, and the positive or negative effect of advertising in the second period $\left(\alpha a_{i 1 k}\right)$. The parameter $\alpha$ denotes the LT effect of retail local advertising on consumers' marginal utility. We have assumed that the marginal impact of local advertising undertaken by each retailer is the same for each product in the $\mathrm{LT}$, as retailers tend to use the same local media for their promotional activities. This parameter can be set to zero when first-period local advertising does not impact consumers' utility in the second period. It can take positive values $(\alpha>0)$ when the type of local advertising activities undertaken contribute to stimulating repeat purchase. Finally, it can also take negative values $(\alpha<0)$ when local advertising damages product preference and quality perception over time (Ataman et al., 2010; DelVecchio et al., 2006; Herrington and Dempsey, 2005; Guyt and Gijsbrechts, 2020). This is based on empirical evidence that advertising and promotion activities impact 
the consumer utility intercept over time (Sriram et al., 2007). Our formulation assumes that retailers and manufacturers are symmetric. This implies that the retailers and products are fairly similar, and the effects of retailers' local advertising on consumer evaluations of the different products are identical.

The interpretation of the different utility parameters can be easily inferred by looking at the marginal utility of consumption for each product $i$ in each period $j$ and at each store $k: \frac{\partial U_{j}}{\partial d_{i j k}}=g+f_{j}\left(a_{i j k}\right)-d_{i j k}-\theta d_{(3-i) j k}-\beta d_{i j(3-k)}-p_{i j k}, i, k, j=1,2$. The parameter $\theta \in[0,1)$ denotes the rate of decline of marginal utility of consumption for one product with respect to the consumption of the competing product sold at the same store. It represents the degree of substitutability or the intensity of competition between the two products. When the two products are perfectly differentiated, $\theta=0$. Otherwise, consumers who patronize a given store find some level of substitutability between the two products.

Finally, the parameter $\beta \in[0,1)$ is the rate of decline of marginal utility of consumption for one product with respect to the consumption of the same product sold at the competing store. It represents the level of competition between stores. This parameter captures the extent to which consumers care about where they make their purchases. In particular, when $\beta=0$, competition between stores for each product does not exist. This means that consumers are attached to stores where they make their purchases. Possible explanations for consumer attachment to stores can include store location and the type of associated services they provide.

The demand functions are obtained by maximizing the above consumer utility function. In each period $j$, the utility-maximizing consumer will optimally allocate the quantities consumed by solving the first-order conditions: $\frac{\partial U_{j}}{\partial d_{i j k}}=0$ for $i, k=1,2$. Solving these conditions, we obtain the following demand functions for $i, k=1,2$ :

$$
\begin{aligned}
d_{i 1 k}= & \gamma+\delta\left(p_{i 1 k}-a_{i 1 k}\right)+\epsilon\left(p_{i 1(3-k)}-a_{i 1(3-k)}\right)+\eta\left(p_{(3-i) 1 k}-a_{(3-i) 1 k}\right) \\
& +\lambda\left(p_{(3-i) 1(3-k)}-a_{(3-i) 1(3-k)}\right), \\
d_{i 2 k}= & \gamma+\delta\left(p_{i 2 k}-\alpha a_{i 1 k}\right)+\epsilon\left(p_{i 2(3-k)}-\alpha a_{i 1(3-k)}\right)+\eta\left(p_{(3-i) 2 k}-\alpha a_{(3-i) 1 k}\right) \\
& +\lambda\left(p_{(3-i) 2(3-k)}-\alpha a_{(3-i) 1(3-k)}\right)
\end{aligned}
$$

where

$$
\begin{aligned}
& \gamma=g\left[(1-\beta)^{2}-\theta^{2}\right](1+\beta-\theta) / \mu, \quad \delta=-\left(1-\beta^{2}-\theta^{2}\right) / \mu \\
& \epsilon=\beta\left(1-\beta^{2}+\theta^{2}\right) / \mu, \quad \eta=\left(1+\beta^{2}-\theta^{2}\right) \theta / \mu, \quad \lambda=2 \beta \theta / \mu
\end{aligned}
$$

and the abbreviated expression $\mu$ is such that $\mu=\left[1-(\beta-\theta)^{2}\right]\left[1-(\theta+\beta)^{2}\right]$.

The above demand system is economically meaningful provided the following conditions are satisfied: the market potential is positive $(\gamma>0)$, own-price effect on demand is negative $(\delta<0)$, cross-price effect is positive $(\min (\epsilon, \eta, \lambda)>0)$, own-price effect is larger than all other prices' effects $(|\delta|>\max (\epsilon, \eta, \lambda))$, and local advertising exhibits opposite effects on demand compared with price, which is verified in this case. Given that $\beta, \theta \in(0,1)$, it is easy to demonstrate that these restrictions are satisfied when the following condition is verified: $1-\beta^{2}-\theta^{2}>0$. This condition means that demand will not be economically viable, as defined above, if both store and product substitutability levels are high. We assume this condition to be true in the rest of the paper.

As we can see, the demand functions in the first period depend on the advertis- 
ing efforts and on the prices of each product in each retail store in period 1 . The second-period demands depend on the second-period prices and on the first-period advertising efforts for each product in each retail store. Note that the market potential, $\gamma$, and all demand sensitivity parameters $(\delta, \epsilon, \eta$, and $\lambda)$ depend on both product and store substitutability parameters $(\beta$ and $\theta)$ in both periods. In the second period, demand sensitivity to advertising also depends on the LT effect of advertising $(\alpha)$. Our consumer utility-derived demand functions allow us to represent the effect of substitutability between products and stores separately. This cannot be fully captured with a conventional linear demand function formulation that is not derived from a consumer utility function, where $\gamma, \delta, \epsilon, \eta$, and $\lambda$ are the main model parameters (see Lus and Muriel (2009) for more discussion on the value of utility-based demand formulation).

To get better insights from the demand equations and to study the effect of product and store competition in our analysis of cooperative advertising, we look at some special cases. Notably, if the two products do not compete, in other words are fully differentiated $(\theta=0)$, then all demand parameters related to product competition would be null $(\eta=\lambda=0)$, and the demand function takes the following form for $i, k=1,2$ :

$$
\begin{aligned}
d_{i 1 k}^{\theta=0} & =\frac{1}{1-\beta^{2}}\left[g(1+\beta)-\left(p_{i 1 k}-a_{i 1 k}\right)+\beta\left(p_{i 1(3-k)}-a_{i 1(3-k)}\right)\right], \\
d_{i 2 k}^{\theta=0} & =\frac{1}{1-\beta^{2}}\left[g(1+\beta)-\left(p_{i 2 k}-\alpha a_{i 1 k}\right)+\beta\left(p_{i 2(3-k)}-\alpha a_{i 1(3-k)}\right)\right] .
\end{aligned}
$$

When the two stores are fully differentiated $(\beta=0)$, all demand parameters related to store competition would be null $(\epsilon=\lambda=0)$, and the demand function becomes for $i, k=1,2$ :

$$
\begin{aligned}
d_{i 1 k}^{\beta=0} & =\frac{1}{1-\theta^{2}}\left[g(1-\theta)-\left(p_{i 1 k}-a_{i 1 k}\right)+\theta\left(p_{(3-i) 1 k}-a_{(3-i) 1 k}\right)\right], \\
d_{i 2 k}^{\beta=0} & =\frac{1}{1-\theta^{2}}\left[g(1-\theta)-\left(p_{i 2 k}-\alpha a_{i 1 k}\right)+\theta\left(p_{(3-i) 2 k}-\alpha a_{(3-i) 1 k}\right)\right] .
\end{aligned}
$$

\subsection{Profit functions}

As in many other papers in the marketing literature, we use convex costs to take into account increasing marginal costs of advertising. In the CA game, each manufacturer $i$ offers a cooperative advertising support rate, $s_{i}$, to retailers. Manufacturer $i$ 's portion of retailer $k$ 's local advertising expenses for her brand is $s_{i} a_{i 1 k}^{2}$, while the retailer $k$ 's remaining local advertising cost for the brand $i$ is $\left(1-s_{i}\right) a_{i 1 k}^{2}$.

The manufacturers and retailers determine their decisions so as to maximize their respective profits over the two-period planning horizon. In the CA game, where manufacturer $i$ offers a cooperative advertising program in period 1 , her first-period profit function, $M_{i 1}, i \in\{1,2\}$, and the retailer $k$ 's first-period profit for the two brands, $R_{1 k}, k \in\{1,2\}$, are given by:

$$
\begin{aligned}
M_{i 1} & =\sum_{k=1,2}\left(w_{i 1} d_{i 1 k}-s_{i} a_{i 1 k}^{2}\right) \\
R_{1 k} & =\sum_{i=1,2}\left[\left(p_{i 1 k}-w_{i 1}\right) d_{i 1 k}-\left(1-s_{i}\right) a_{i 1 k}^{2}\right] .
\end{aligned}
$$


Their respective second-period profits, $M_{i 2}$ and $R_{2 k}$, are:

$$
\begin{aligned}
M_{i 2} & =\sum_{k=1,2}\left(w_{i 2} d_{i 2 k}\right) \\
R_{2 k} & =\sum_{i=1,2}\left[\left(p_{i 2 k}-w_{i 2}\right) d_{i 2 k}\right] .
\end{aligned}
$$

Setting the cooperative advertising support rate to zero $\left(s_{i}=0\right)$ in the first-period profit functions provided above, one obtains the corresponding expressions in the NCA game where the manufacturers do not offer cooperative advertising programs. Finally, the above formulation assumes that the retailers do not stockpile and only order the quantities of products that they can effectively sell in each period.

\section{Results}

In this section, we obtain the equilibrium solutions and assess the effects of cooperative advertising programs. The general model is very complex due to the extensive number of parameters and decision variables involved and cannot be fully investigated analytically. To generate some analytical insights, we first obtain results for the two simplified versions (particular cases) of this model where either of the two parameters $\theta$ and $\beta$ is set to zero. The analysis of the general model for $\theta, \beta \neq 0$ will be performed in the last subsection.

In each case, we obtain subgame-perfect equilibrium solutions using backward induction for the NCA and the CA games. These equilibria do not require commitment about pricing and advertising decisions, and they are time consistent since manufacturers, as channel leaders, do not have any incentive to deviate from their announced pricing and advertising policies. We then identify the conditions on the model's parameters for which an interior equilibrium solution is obtained. These conditions guarantee strictly positive margins, prices, advertising efforts, support rate $s<1$, demands, and profits at equilibrium, as well as strictly concave objective functions (profits) for manufacturers and retailers with respect to their decision variables. When at least one of these conditions is not satisfied, a game is considered unfeasible and the solution cannot be implemented. All proofs are in the Appendices.

\subsection{Particular case 1: Products are perfectly differentiated $(\theta=0)$}

This case corresponds to the situation where the two products are perfectly differentiated and therefore do not compete with each other (e.g., computer manufacturer and camera manufacturer). However, two retailers, such as Staples and Best Buy, selling these two products in the same neighbourhood, compete with each other since customers can choose to buy these products from one or the other $(\beta \neq 0)$.

The demand functions for $\theta=0$ are given by equations (3) and (4). In this case, we are able to analytically characterize the unique interior equilibrium solutions for both the CA and NCA games. For simplicity, we include these expressions in an appendix (see Appendix A for details). Note that while there is no product competition in this case, the results are not equivalent to modelling a supply chain with one manufacturer and two retailers. This is because we solve both manufacturers' problems, which affect retailers' pricing and advertising decisions. 
To identify the impact of cooperative advertising on the players' profits in the case of perfectly differentiated products, we compare the equilibrium solutions of the NCA and CA games when they are both feasible. The findings of our analytical inquiry are summarized in the following proposition.

Proposition 1. When products are perfectly differentiated $(\theta=0)$, the manufacturers' profits over both periods are higher in the CA game than in the NCA game, in other words,

$$
\Pi_{M}^{C A}>\Pi_{M}^{N C A}
$$

Proposition 1 shows that cooperative advertising always benefits the manufacturers of perfectly differentiated products regardless of the nature of the long-term effects of retail advertising. This result can be explained by analyzing the impact of $\mathrm{CA}$ on equilibrium strategies (see Proposition 4 in Appendix B). In fact, when cooperative advertising is offered, competitive retailers increase their advertising investments in the first period. This is in line with managerial practice, as CA acts as an incentive to boost retail advertising activities. Given that higher advertising efforts increase demand, retailers also charge higher first-period prices. In this case, retailers take advantage from the positive effect of advertising on consumer utility to increase prices at equilibrium. Despite the increase in first-period prices, the first-period demands are ultimately expanded. Further, to compensate for their cooperative advertising costs and to overcome any possible negative impact of retail advertising in the second period, manufacturers charge higher wholesale prices in the first period. The additional manufacturers' revenue compensates for the added cost created by the cooperative advertising program and ultimately results in higher manufacturers' profits overall.

The comparison of the retailers' profits for the NCA and CA games is more complex and does not lead to analytical insights. We therefore resort to numerical simulations for 100 different values of $\alpha$, in the interval $(-1,1)$ (a mesh of 0.02 ), and 100 different values of $\beta$ in the interval $(0,1)$ (a mesh of 0.01 ) while fixing $g=1$ without loss of generality. This leads to a numerical analysis of the expression $\left(\Pi_{R}^{\mathrm{NCA}}-\Pi_{R}^{\mathrm{CA}}\right)$ for 10,000 value combinations of parameters $\alpha$ and $\beta$. The comparisons are conducted exclusively in areas of the parameter space where both the NCA and CA games are feasible. The next claim summarizes the numerical findings.

Claim 1. When products are perfectly differentiated $(\theta=0)$, retailers prefer the $N C A$ game to the CA game, in other words,

$$
\Pi_{R}^{C A}<\Pi_{R}^{N C A}
$$

Thus, in the case of perfectly differentiated products, retailers are always better off when they do not participate in manufacturers' cooperative advertising programs. Any gain they may realize in terms of margin or/and demand increase due to their participation in cooperative advertising programs is lost in the additional advertising expenditures they have to incur, which ultimately intensifies the advertising war between them (see Proposition 4 in Appendix B). In this case, the nature of the long-term effects of retail advertising does not affect retailers' preferences.

Compared with previous studies that only accounted for retail competition, our results generalise the findings in Sigué and Chintagunta (2009) to a setting where the supply chain includes a second differentiated manufacturer, retail advertising can 
generate negative effects, and prices are endogenous decision variables. While we find similar results to Chutani and Sethi (2012) for the manufacturers, our results diverge as to the impact of cooperative advertising for retailers. Also, our findings differ from Karray and Amin (2015) who found that retailers could benefit from cooperative advertising for high levels of competition between stores in a static setting. Finally, Huang et al. (2018) was the only work that modelled the long-term effect of retail advertising in one-manufacturer, two-retailer supply chain. These authors did not assess the impact of cooperative advertising for retailers but showed numerically that the manufacturer benefits from the cooperative agreement when retail advertising is not too harmful, and loses otherwise. This divergence in our findings can be explained by our different modelling approach, since we solve for prices while Huang et al. (2018) did not. Supply chain members adjust their pricing decisions following the implementation of cooperative advertising programs, which makes it possible for manufacturers to alleviate any harmful impact of these programs.

\subsection{Particular case 2: Retailers are perfectly differentiated $(\beta=0)$}

The case $\beta=0$ corresponds to the situation in which two competitive products (e.g., Dell and HP computers) are sold by two perfectly differentiated retail stores. Among others, retail differentiation may be due to remoteness, such that consumers who patronize one retail store find it difficult to consider the other as an alternative. Each retailer is in a relative local monopoly situation.

The demand functions for $\beta=0$ are given by equations (5) and (6). In this case, we are able to analytically characterize the unique interior equilibrium solutions for both the CA and NCA games. For simplicity, we include these expressions in the appendix (see Appendix B for details). The manufacturers' optimization problems take into account both retailers' sales and cooperative costs (in the CA game). Therefore, this case extends the model in Karray et al. (2017a) who considered two manufacturers selling to a single retailer to the case of two non-competing retailers.

To examine the impact of cooperative advertising, we compare the analytical expressions of the players' profits for the two games using numerical analysis for a combination of 1,000 different values of $\alpha$ in the interval $(-1,1)$ and 1,000 different values of $\theta$ in the interval $(0,1)$. The comparisons are conducted exclusively in areas of the parameter space where both the NCA and CA games are feasible (i.e., interior equilibrium conditions are verified). We present the findings of these comparisons in the following claim.

Claim 2. When retailers are perfectly differentiated $(\beta=0)$, whether manufacturers and retailers benefit or not from cooperative advertising depends on the values of the parameters $\alpha$ and $\theta$.

To illustrate the result in this claim, we refer to Figure 1 which reveals that when stores are perfectly differentiated, manufacturers and retailers may face four different situations. In the first, manufacturers prefer the CA game, while retailers are better off playing the NCA game $\left(\Pi_{M}^{\mathrm{CA}}>\Pi_{M}^{\mathrm{NCA}}\right.$ and $\left.\Pi_{R}^{\mathrm{CA}}<\Pi_{R}^{\mathrm{NCA}}\right)$. This mostly happens when the products are highly differentiated $(\theta<0.2)$. In the second situation, both manufacturers and retailers prefer the CA to the NCA game $\left(\Pi_{M}^{\mathrm{CA}}>\Pi_{M}^{\mathrm{NCA}}\right.$ and $\Pi_{R}^{\mathrm{CA}}>$ $\left.\Pi_{R}^{\mathrm{NCA}}\right)$ when the products are moderately substitutable $(0.2<\theta<0.3)$ and first-period retailer advertising expands second-period demands. Third, both manufacturers and retailers prefer the NCA game to the $\mathrm{CA}$ game $\left(\Pi_{M}^{\mathrm{CA}}<\Pi_{M}^{\mathrm{NCA}}\right.$ and $\left.\Pi_{R}^{\mathrm{CA}}<\Pi_{R}^{\mathrm{NCA}}\right)$ when 
the products are moderately substitutable and first-period retailer advertising reduces second-period demands. Finally, manufacturers prefer the NCA game, while retailers are better off playing the CA game $\left(\Pi_{M}^{\mathrm{CA}}<\Pi_{M}^{\mathrm{NCA}}\right.$ and $\left.\Pi_{R}^{\mathrm{CA}}>\Pi_{R}^{\mathrm{NCA}}\right)$, especially when the products are relatively highly substitutable $(\theta>0.3)$.

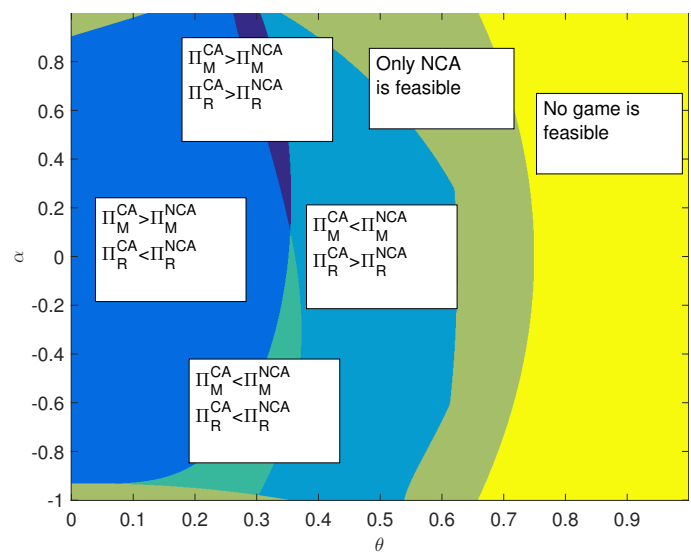

Figure 1. Comparison of manufacturers' and retailers' optimal profits in the different games $(\beta=0)$

These results are qualitatively different from those reported in Karray et al. (2017a). In particular, these authors found that cooperative advertising mostly benefits two competing manufacturers and a single retailer even when retail advertising generates negative effects in the second period. Contrary to these results, we find that the retailers do not benefit from cooperative advertising for $\alpha<0$. Further, both manufacturers and retailers simultaneously prefer cooperative advertising only in a small area where; (i) the first-period retail advertising generates high enough positive LT impact, and (ii) the manufacturers' products are moderately substitutable. Finally, as we can see in Figure 1, cooperative advertising is only beneficial to manufacturers for $\theta<0$.4. This threshold is larger in Karray et al. (2017a) (higher than 0.5). Therefore, the required level of competition between products that ensures the profitability of cooperative advertising for manufacturers decreases with the number of retailers. Qualitatively, however, the two works are consistent in that cooperative advertising is less (more) attractive to manufacturers (retailer(s)) when the competition between products is relatively high.

\subsection{General model}

We now turn to the general model for which the demand functions are given in Equations (1) and (2). Contrary to the two previous particular cases, this formulation allows for substitutability both between products and between stores. An example in this case is Staples and Best Buy stores located in the same neighbourhood and selling HP and Dell computers.

We obtain and characterize a unique interior equilibrium solution in the NCA game (see Appendix C). However, we are unable to obtain a closed-form equilibrium solution in the CA game. Therefore, we resort to numerical analyses. With the help of Mathematica 11.0.1.0, we express the retailers' and manufacturers' optimal strategies as functions of the cooperative advertising support rates, $s_{1}$ and $s_{2}$. Because of the symmetric nature of the game, we look for symmetric equilibria by solving a nonlinear equation for a common cooperative advertising support rate, $s=s_{1}=s_{2}$. 
We develop a numerical algorithm in Matlab R2014b to identify the possible solutions to this equation and carry out several simulations. We consider the following values for the parameter $\beta$ : $0.1,0.2,0.3,0.5,0.7$, and 0.9 . For each of these values, we solve the nonlinear equation characterizing the optimal value of $s$ for different values of $\alpha$ and $\theta$. In particular, we solve this nonlinear equation for 100 different values of $\alpha$ in the interval $(-1,1)$ and 100 different values of $\theta$ in the interval $(0,1)$. For each of these $100 \times 100$ pairs $(\theta, \alpha)$, we solve the nonlinear equation considering different initial values of $s$ in the interval $(0,1]$ (1000 initial values of $s$ for each pair $(\theta, \alpha)$ are considered). Note that, in some cases, for the same value of the pair $(\theta, \alpha)$, the nonlinear equation may have multiple solutions or multiple equilibria. We make sure that the positivity and concavity conditions are satisfied for each of the obtained equilibria. These conditions guarantee concave manufacturers, and retailers' problems, positive equilibrium solutions, and a positive support rate $s<1$ (feasibility conditions). When multiple equilibria are feasible, the numerical algorithm is set to select the support rate, $s$, that generates the greatest profits for the manufacturers' as supply chain leaders.

The results obtained from our numerical simulations are hereafter presented in claims and illustrated through examples provided in Figures 2 to 6 for specific values of $\beta=0.1,0.3,0.7, \alpha \in(-1,1)$, and $\theta \in(0,1)$.

We start by analysing the feasible domains of the optimal solutions of the NCA and CA games. The examples in Figure 2 show that the feasible domains of both the NCA and CA games shrink as the parameter $\beta$ takes larger values. In other words, the two games are less likely to be played if the retailers become highly substitutable. Further, given the level of competition between retailers, the two games are less likely to be played when the parameter $\theta$ takes relatively large values or the two brands are highly substitutable. Also, everything else being equal, both the NCA and CA games can be feasible regardless of the nature and intensity of the long-term advertising effects. This finding suggests that the fact that local advertising can harm future sales should not, on its own, prevent manufacturers from supporting it. Note also that the CA game always has a smaller feasible domain than does the NCA game. In addition, the feasibility conditions of the CA game imply the fulfillment of those of the NCA game. Finally, the feasibility of either of the two games depends on the combination of the long-term effects of local advertising, and on the levels of competition between brands and between retailers.

\subsubsection{Sensitivity analysis of the support rate}

We focus here on the cooperative support rate, $s$, in the CA game. In particular, for all feasible values of $s$ at equilibrium, we study the effect of changes in the main model parameters, $\alpha, \theta$, and $\beta$ on $s$.

The sensitivity analysis of $s$ with respect to parameters $\alpha$ and $\theta$ is carried out by fixing the value of $\beta$ as previously described. For each value of $\beta$, we generate a grid for different values of $\alpha$ and $\theta$ such that there are 100 different values of $\alpha$ in the interval $(-1,1)$ and 100 different values of $\theta$ in the interval $(0,1)$. For each of these $100 \times 100$ pairs $(\theta, \alpha)$ that belong to the area where scenario CA is feasible, we compute the sign of the derivative of $s$ with respect to $\alpha$ and $\theta$. The sensitivity analysis of the support rate $s$ with respect to parameter $\beta$ is carried out locally. Following the same procedure described before for each fixed value of $\beta$, denoted as $\tilde{\beta}$, we analyse the sign of the derivative of $s$ with respect to $\beta$ near $\tilde{\beta}$. This derivative has been computed for each of the $100 \times 100$ pairs $(\theta, \alpha)$ that belong to the area where scenario $\mathrm{CA}$ is feasible. These simulations lead to the following numerical results. 

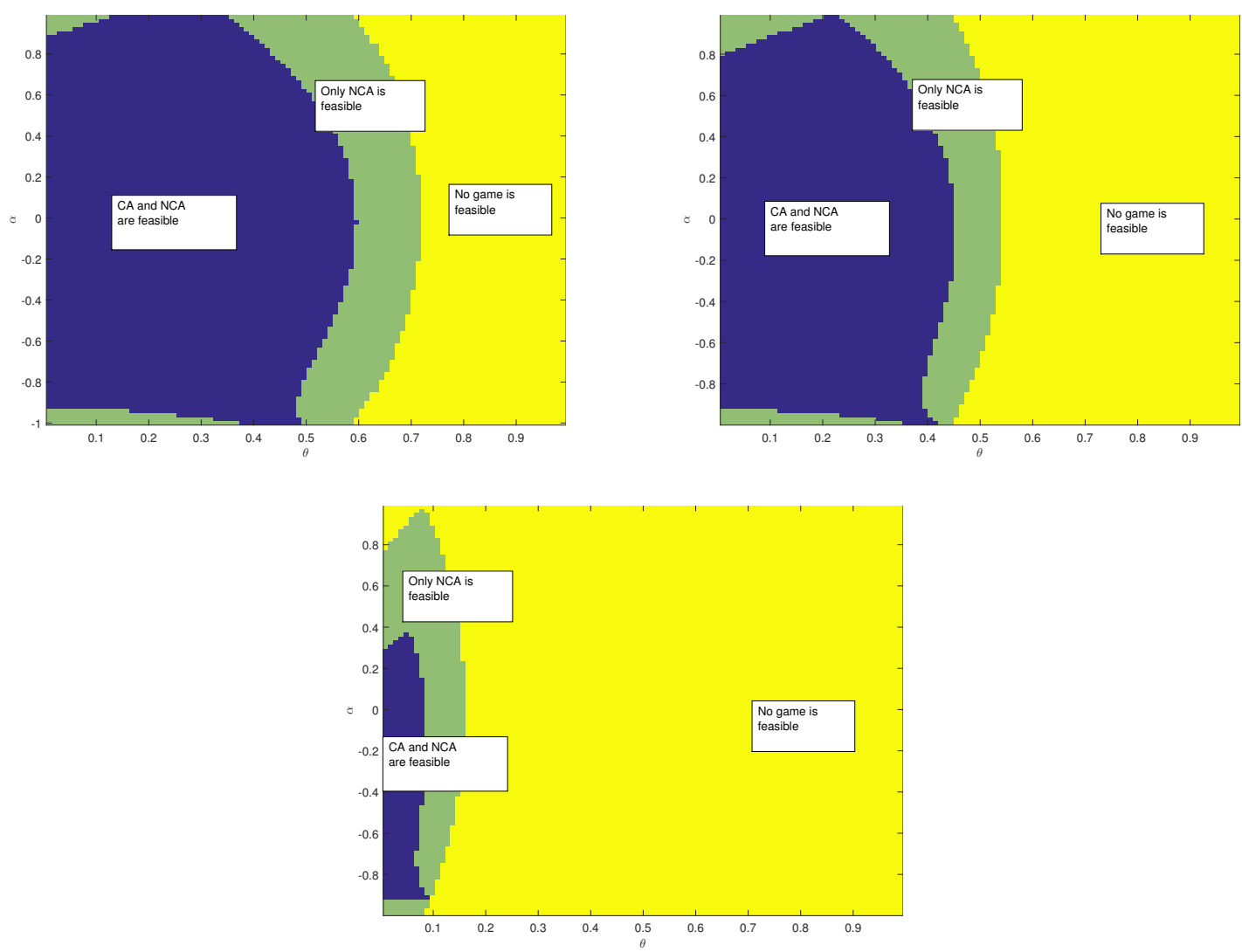

Figure 2. $\quad$ Feasible and unfeasible regions for both games $\beta=0.1$ (upper left); $\beta=0.3$ (upper right); $\beta=0.7$ (lower).

Claim 3. In the general game where $\theta, \beta \neq 0$, the sensitivity analysis of the support rate, $s$, with respect to the model parameters, is as follows:

1. The support rate, $s$, always increases with $\alpha$.

2. The support rate, $s$, increases with $\theta$ if $\alpha>0$ and decreases with $\theta$ if $\alpha<0$.

3. The support rate, $s$, can increase or decrease with $\beta$.

The first finding suggests that, as expected, the manufacturers' cooperative advertising support rate increases as the LT advertising effect becomes stronger. The second result indicates that the level of competition between the manufacturers' products influences their cooperative advertising support rate differently, depending on whether the LT advertising effects are positive or negative. When advertising positively affects future consumer utility for the product $(\alpha>0)$, manufacturers should provide a larger support rate to their retailers at equilibrium when their products are close competitors than when their products are differentiated. Alternatively, when advertising negatively affects consumers' utility for the product $(\alpha<0)$, manufacturers' support rate should be lower with higher levels of product competition.

Finally, the effect of store competition on the support rate depends on the LT effects of advertising and on the level of product competition. Figure 3 provides an illustration of these results. As we can see, for low levels of product competition, the effect of changes in $\beta$ on $s$ is mostly negative for positive LT advertising effects and can be positive or negative for $\alpha<0$. These effects are reversed when product competition is high, meaning that differentiation between the manufacturers' products is low. In 

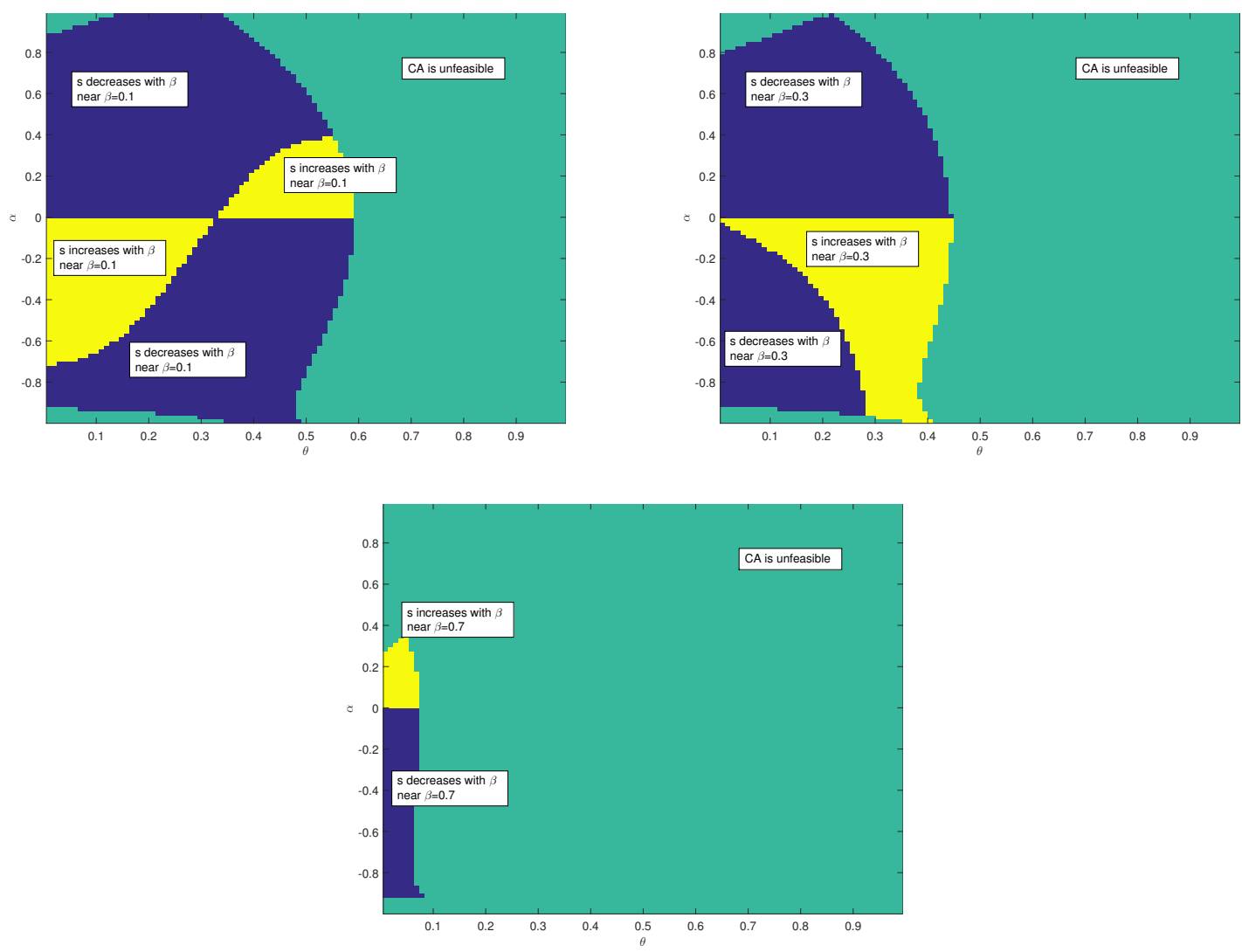

Figure 3. Sensitivity analysis of the support rate with respect to $\beta$ near $\beta=0.1$ (upper left); $\beta=0.3$ (upper right); $\beta=0.7$ (lower).

this case, the support rate increases with $\beta$ for positive LT advertising effects and mostly decreases with higher values of $\beta$ for $\alpha<0$.

We now compare the optimal outcomes of the NCA and $\mathrm{CA}$ games in order to identify the impact of cooperative advertising in the context of the general model. In particular, we examine how cooperative advertising affects the strategies and profits of both manufacturers and retailers over the two-period planning horizon.

\subsubsection{Comparison of equilibrium strategies}

Numerical simulations are conducted to identify how the players' decisions as well as the retailers' margins, $m_{j}, j \in\{1,2\}$, and demands both in the first and second periods compare in the NCA and CA games for $\beta=0.1,0.2,0.3,0.5,0.7$, and 0.9 , as well as $\alpha \in(-1,1)$, and $\theta \in(0,1)$. We find the following numerical results.

Claim 4. In the general game where $\theta, \beta \neq 0$, regardless of the parameters' values, the first-period retail prices, advertising efforts, margins, and demands in the NCA and CA games compare as follows:

$$
\begin{aligned}
& p_{1}^{C A}>p_{1}^{N C A}, \quad a_{1}^{C A}>a_{1}^{N C A}, \quad m_{1}^{C A}>m_{1}^{N C A}, \quad d_{1}^{C A}>d_{1}^{N C A}, \\
& p_{2}^{C A} \geq p_{2}^{N C A}, \quad w_{2}^{C A} \geq w_{2}^{N C A}, \quad m_{2}^{C A} \geq m_{2}^{N C A}, \quad d_{2}^{C A} \geq d_{2}^{N C A} \quad \text { iff } \quad \alpha \geq 0 .
\end{aligned}
$$

The comparison of first-period wholesale prices in the CA and NCA games shows that, in most areas of the feasible parameter space (dark blue-coloured area), the 
first-period wholesale prices are higher in the CA than in the NCA game (i.e., $w_{1}^{C A}>$ $\left.w_{1}^{N C A}\right)$. The exception in this case is that for small values of the parameter $\beta(\beta<0.3)$, the first-period wholesale prices can also be higher in the NCA game than in the CA game. Figure 4 provides an illustration of this result for $\beta=0.1$. It shows that high product substitutability combined with highly negative long-term advertising effects lead to lower wholesale prices with CA.

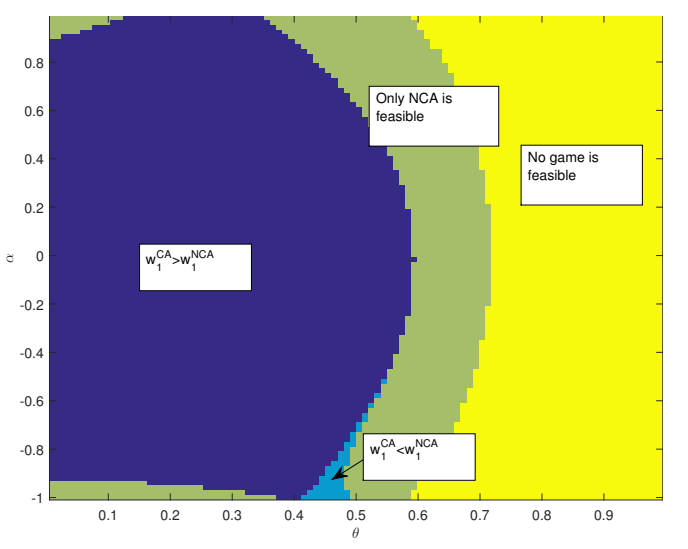

Figure 4. Comparison of first-period optimal wholesale prices in the different games $(\beta=0.1)$

The findings illustrated in Figure 4 suggest that the manufacturers' cooperative advertising programs stimulate more advertising investments from retailers, which expand the demands for the two products at the retail level and allow the retailers to increase their retail prices. Because of the symmetric nature of the models, retailers' advertising could be viewed as generic advertising that expands the baseline demand for the product category and benefits equally the sales of the two manufacturers and retailers. Therefore, in such a context, the manufacturers' cooperative advertising programs contribute to lessening retail price competition, regardless of the level of differentiation of the two products and retail outlets. However, as illustrated in Figure 4, cooperative advertising can also intensify first-period wholesale price competition when advertising significantly damages second-period sales and the two products are highly substitutable in the feasible domain (light blue-coloured area). In this case, the intensification of wholesale price competition only benefits the retailers who maintain higher retail prices in the CA game.

The comparisons of the second-period decisions and outcomes critically depend on the nature of the LT effects of the first-period advertising efforts, $\alpha$. In particular, if advertising generates no carryover effect (i.e., $\alpha=0$ ) the second-period prices, margins, and demands are identical in the NCA and CA games. Alternatively, if first-period advertising positively (negatively) affects the second-period sales or expands (diminishes) the baseline demands for the products, the second-period prices, margins, and demands are higher (lower) in the CA game than in the NCA game. This finding holds regardless of the levels of differentiation of the products and retail outlets. In other words, cooperative advertising may intensify (reduce) second-period price competition between manufacturers and retailers if advertising contributes to diminishing (expanding) post-advertising sales. 


\subsubsection{Comparison of equilibrium profits}

We numerically compare the players' profits in the NCA and CA games for $\beta=$ $0.1,0.2,0.3,0.5,0.7$, and 0.9 . We consider 100 different values of $\alpha$ in the interval $(-1,1)$ and 100 different values of $\theta$ in the interval $(0,1)$. For each value of $\beta$ and each of these $100 \times 100$ pairs $(\alpha, \theta)$, we numerically compare the players' profits in the NCA and $\mathrm{CA}$ games.

Claim 5. In the general game where $\theta, \beta \neq 0$, the profitability of cooperative advertising programs for the manufacturers mostly depends on the levels of differentiation between the two products and between the two retailers.

Figure 5 illustrates the results for the comparisons of the manufacturers' profits. As we can see, when the products and retailers are both well differentiated (i.e., low $\beta$ and $\theta$ ), cooperative advertising enhances the manufacturers' profits. In this case, the products as well as the retailers are in quasi-monopolistic situations. The advertising support provided by each manufacturer benefits her product quasi-exclusively, as no retailer feels the need to attract the rival's customers. For relatively high levels of store differentiation (low $\beta$ ), meaning that consumers are attached to retail outlets, cooperative advertising becomes less attractive for the manufacturers when their products become more substitutable (high $\theta$ ). Manufacturers engage, via their cooperative advertising programs, in an advertising war that pushes the retailers to advertise their products more than necessary. As a result, the manufacturers spend higher amounts to support retailers' advertising than the revenue generated by the incremental retail advertising, due to their cooperative advertising programs.

Conversely, cooperative advertising is always attractive for the manufacturers when the retailers become highly substitutable (large $\beta$ ). As per the feasibility conditions, their products in this case can only be well differentiated. In these conditions, manufacturers do not feel the need to compete heavily on advertising, so they support retail advertising only moderately. The end result is that cooperative advertising costs incurred by the manufacturers are lower than the incremental revenue obtained. These results differ from those provided by the cooperative advertising literature for supply chains with two manufacturers and two retailers. The static models in the literature provide contradicting results. Karray and Zaccour (2007) found that competing manufacturers always benefit from the cooperative program. Considering only product competition, Liu et al. (2014) found that symmetric manufacturers only benefit from such programs for low levels of product competition without solving for the cooperative advertising rate. Using a similar assumption, Karray et al. (2017b) found a positive effect when price competition is high. Chutani and Sethi (2018) found a negative impact using a differential game with symmetric supply chain members and non-strategic prices. Different from these results, Claim 5 shows that when strategic pricing and advertising decisions are considered in a context of both retail and product competition through a utility-based demand, the profitability of cooperative advertising for manufacturers is highly dependent on the competition intensity at both levels of the supply chain.

Claim 6. In the general game where $\theta, \beta \neq 0$, the profitability of cooperative advertising programs for the retailers mostly depends on the levels of differentiation between the two products and between the two retailers.

Similar to the manufacturers' case, this claim shows that the profitability of co- 

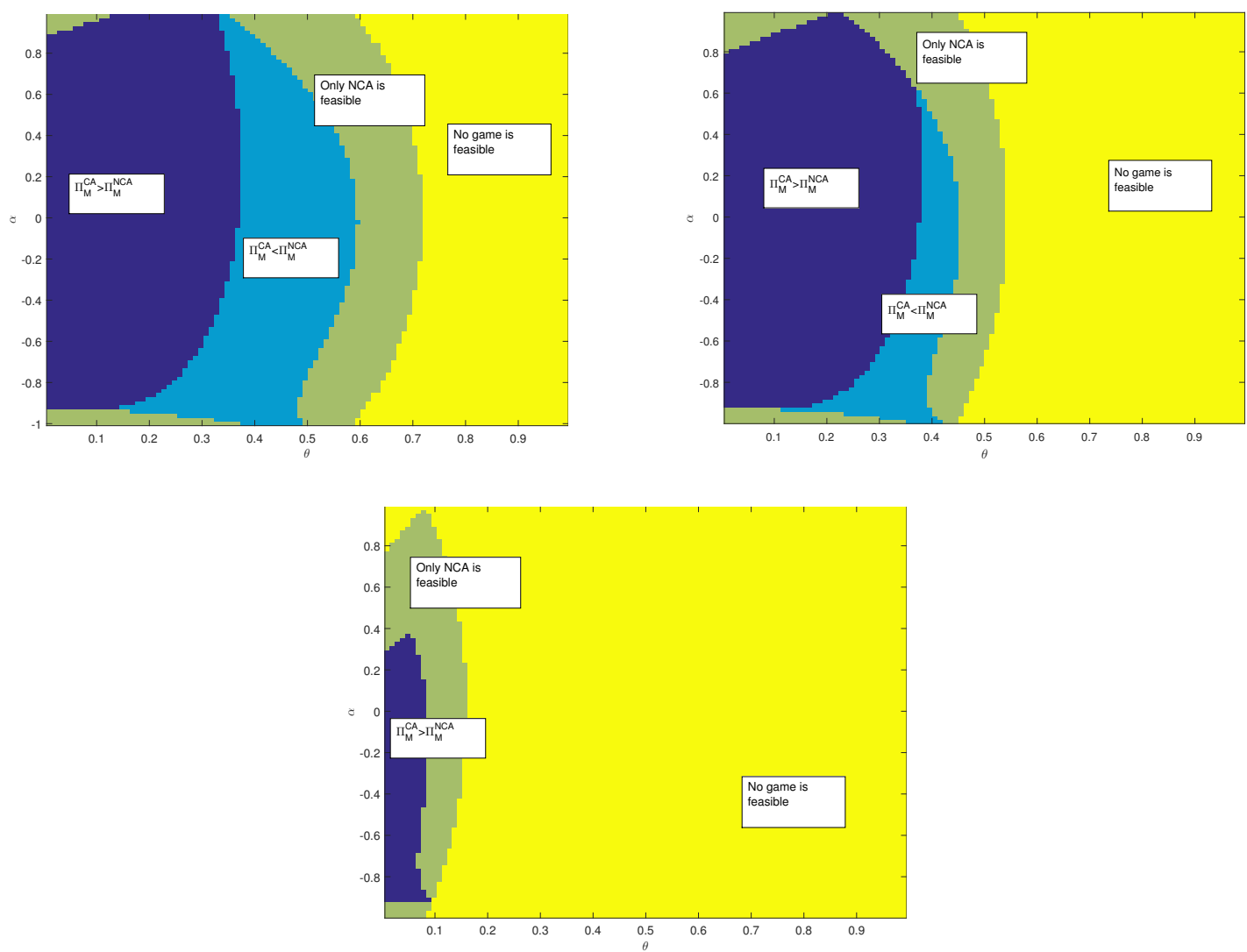

Figure 5. Comparison of manufacturers' optimal profits in the different games. $\beta=0.1$ (upper left); $\beta=0.3$ (upper right); $\beta=0.7$ (lower).

operative advertising programs for the retailers mostly depends on the levels of differentiation between the products and retailers. Figure 6 illustrates the comparisons of the retailers' profits. For the opposite reasons this time, when the products and retailers are both well differentiated (both $\beta$ and $\theta$ are low), cooperative advertising hurts the retailers' profitability. For relatively high levels of store differentiation (low $\beta$ ), cooperative advertising becomes attractive for the competing retailers when the products become more substitutable (higher $\theta$ ). Conversely, cooperative advertising is less attractive for the retailers when they are highly substitutable and the products are relatively well differentiated.

These results can be explained by exploring how cooperative advertising impacts equilibrium strategies (Claim 4). For low $\beta$, the increased cost of advertising, and even the lower second-period revenues in the case of negative LT advertising effect, can be compensated for by the additional first-period retailers' revenues for low enough $\theta$. However, as product substitutability increases, this competitive pressure limits the retailers' gains and ultimately results in losses. For high $\beta$, competitive pressure between retailers leads to insufficient first-period retailers' gains to cover the additional investments in advertising entailed by the cooperative advertising program, regardless of $\alpha$ and second-period retail revenues.

Claim 6 provides different insights to those provided in the related literature. In fact, the impact of cooperative advertising on competing retailers' profitability has been found to be either always positive (Chutani and Sethi, 2018), always negative (Karray et al., 2017b; Liu et al., 2014), or positive for low levels of retail competition 

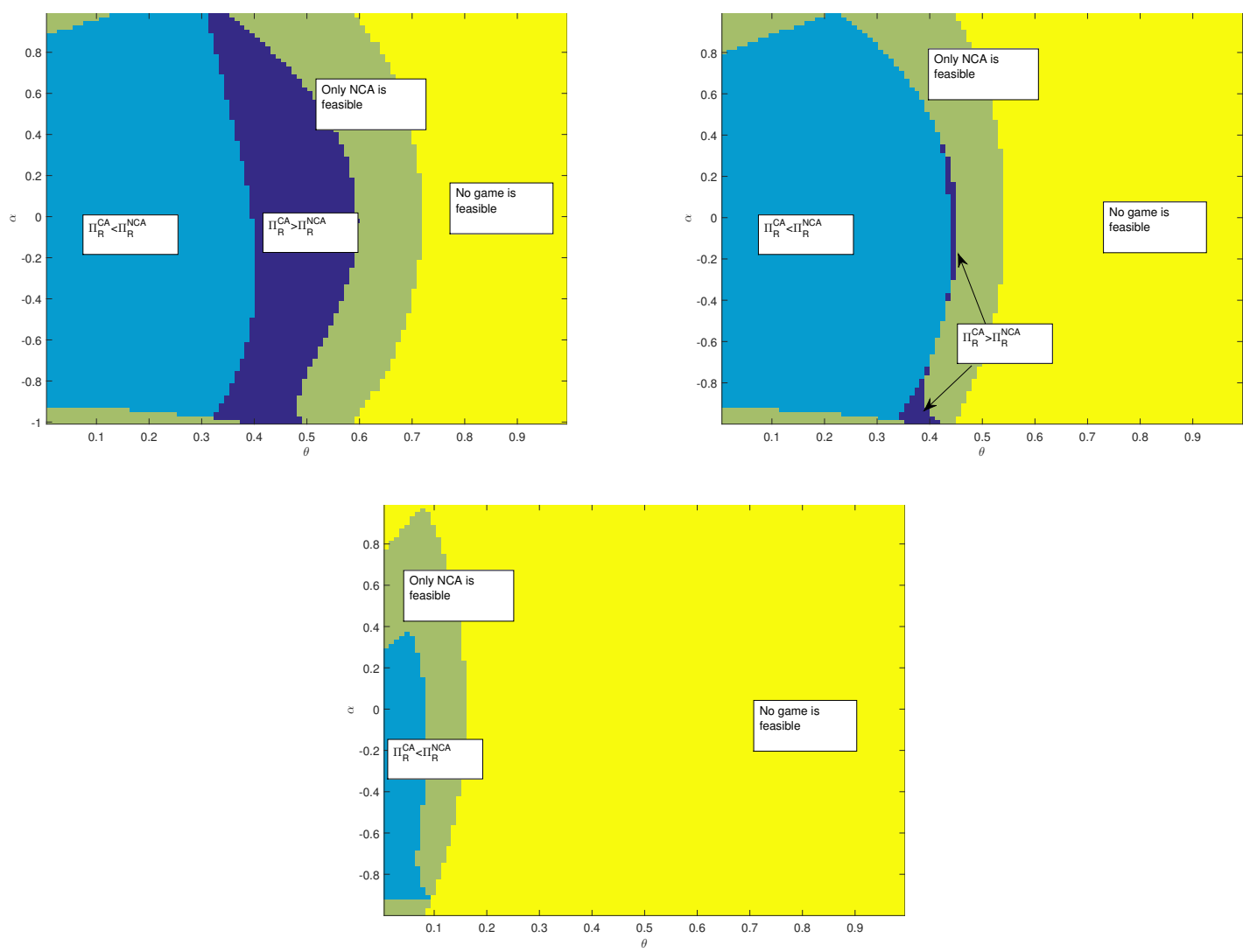

Figure 6. Comparison of retailers' optimal profits in the different games. $\beta=0.1$ (upper left); $\beta=0.3$ (upper right); $\beta=0.7$ (lower).

(Karray and Zaccour, 2007). Our results offer new explanations as to why retailers may not participate in cooperative advertising programs.

Claim 7. In the general game where $\theta, \beta \neq 0$, the manufacturers' and retailers' preferences diverge for the implementation of cooperative advertising programs in most areas of the feasible parameter domain.

Consistent with our analysis from Claims 5 and 6 , in most areas of the feasible parameter domain, the manufacturers' and retailers' preferences diverge. Figure 7 illustrates this claim by combining the findings in Figures 5 and 6 . As we can see, when the manufacturers prefer the CA game, the retailers prefer the NCA game, and vice versa. Note that cooperative advertising agreements are voluntary programs by which manufacturers first announce their rates, then retailers decide to opt in or out (Aust and Buscher, 2014a; Jørgensen and Zaccour, 2014; Karray et al., 2017b). Therefore, cooperative advertising programs can only be implemented when additional incentives, such as side payments, are provided to either party in need. Without such incentives, cooperative advertising is not sustainable. Figure 7 also illustrates that, in some limited areas, both players agree to play either the NCA or the CA game. In particular, the CA game is preferred by both the manufacturers and retailers when the level of store differentiation is very high $(\beta \leq 0.1)$, the products are moderately substitutable $(0.2<\theta<0.3)$, and local advertising has enough positive effects on long-term sales $(\alpha>0.3)$. This is illustrated in the dark blue-coloured area of Figure 7 for $\beta=0.1$. The findings of the case $\beta=0$ presented in Figure 1 are qualitatively 
similar.
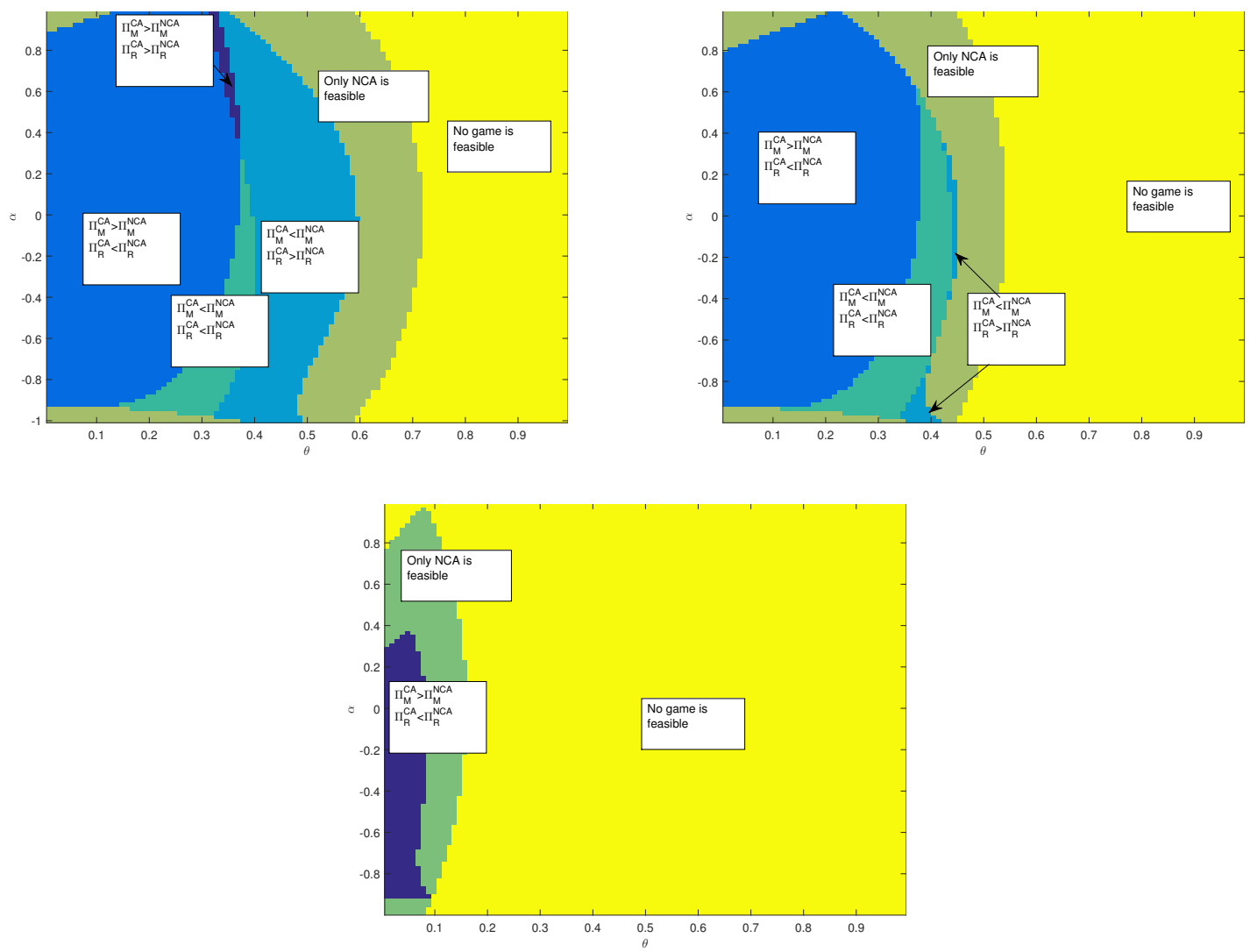

Figure 7. Comparison of manufacturers' and retailers' optimal profits in the different games. $\beta=0.1$ (upper left); $\beta=0.3$ (upper right); $\beta=0.7$ (lower).

In summary, Table 3 shows how the results of our general model compare to existing works in the cooperative advertising literature that model competition at one or more levels of the supply chain.

\section{Conclusion}

This study investigates the profitability of cooperative advertising programs in a supply chain where two competing manufacturers sell their products through two competing retailers. We develop and solve a two-period game-theoretic model that takes into account strategic pricing decisions and allows for positive and negative LT effects of retail advertising. Contrary to the literature about cooperative advertising, our model differentiates between retail and manufacturer competition. It also captures positive as well as negative effects of retail advertising over two periods. Further, it accounts for both advertising and pricing decisions and uses a demand formulation that is derived from maximization of consumer utility. We analyse the profitability of cooperative advertising programs by comparing equilibrium strategies across two games (with and without cooperative advertising) in three scenarios. In two special cases where either products or stores are perfectly differentiated, we obtain closed-form solutions and both analytical and numerical results. In the general case where both products and stores are substitutable, we develop a numerical algorithm to obtain solutions in the 


\begin{tabular}{|c|c|c|}
\hline & $\begin{array}{l}\text { Effect of CA on manufacturer(s) prof- } \\
\text { its }\end{array}$ & Effect of CA on retailer(s) profits \\
\hline \multicolumn{3}{|l|}{1 manufacturer, 2 retailers } \\
\hline Sigué and Chintagunta (2009) & + & - \\
\hline He et al. (2011) & NA & NA \\
\hline Chutani and Sethi (2012) & + & - \\
\hline Chutani and Sethi (2014) & + (depends on margins $)$ & + \\
\hline Aust and Buscher (2014b) & $\mathrm{NA}$ & NA \\
\hline Karray and Amin (2015) & + & +/- (depends on retail competition) \\
\hline Huang et al. (2018) & +/- (depends on LT ad effects) & NA \\
\hline \multicolumn{3}{|l|}{2 manufacturers, 1 retailer } \\
\hline Karray et al. (2017a) & $\begin{array}{l}+/- \text { (depends on retail competition } \\
\text { and LT ad effects) }\end{array}$ & $\begin{array}{l}+/- \text { (depends on retail competition } \\
\text { and LT ad effects) }\end{array}$ \\
\hline \multicolumn{3}{|l|}{2 manufacturers, 2 retailers } \\
\hline Karray and Zaccour (2007) & + & +/- (depends on retail competition) \\
\hline Liu et al. (2014) & + & $+/-$ \\
\hline Karray (2015) & NA & NA \\
\hline Karray et al. (2017b) & $\begin{array}{l}+/- \text { (depends on product competi- } \\
\text { tion) }\end{array}$ & mostly - \\
\hline Chutani and Sethi (2018) & - & + \\
\hline This paper & $\begin{array}{l}+/- \text { (depends on product and retail } \\
\text { competition and LT ad effects) }\end{array}$ & $\begin{array}{l}\text { +/- (depends on product and retail } \\
\text { competition and LT ad effects) }\end{array}$ \\
\hline
\end{tabular}

cooperative advertising game and compare solutions using extensive numerical analysis.

In the general case where both products and stores are substitutable, our findings indicate that whether manufacturers benefit from cooperative advertising mostly depends on the levels of substitutability/differentiation between the two products and stores. In particular, cooperative advertising enhances the manufacturers' profits when the two products and stores are well-differentiated, or their products are well-differentiated and the stores are highly substitutable. Conversely, cooperative advertising is profitable for the retailers when the stores are well-differentiated and the products are highly substitutable. Despite these apparent incompatible preferences between manufacturers and retailers, they can all jointly benefit from cooperative advertising providing that the stores are well differentiated, the products are moderately substitutable, and retailers' advertising generates enough positive LT effects.

This research stresses the importance of considering the LT effects of retailer advertising when assessing cooperative advertising programs for bilateral oligopolies. A key finding of this research is that manufacturers should not consider cooperative advertising in this channel structure as an effective channel coordination mechanism when retailer advertising does not affect, or when it hurts post-advertising consumer utility. In that sense, our research adds to Karray and Zaccour (2007), who investigated this same channel structure in a static one-period game and disregarded LT advertising effects. Our findings support the view that, under some conditions, cooperative advertising may be used to align the interests of manufacturers and retailers when retail advertising generates enough LT positive impact, which benefits all supply chain firms. Conversely, manufacturers should not support retail advertising that negatively affects future sales. A company such Mitsubishi Motors is therefore right to ban this type of retail advertising from its cooperative advertising programs. We also find that manufacturers should increase or decrease their advertising support to retailers with the level of product differentiation, depending on whether retail advertising generates positive or negative LT effects. Static one-period game models, such as those reviewed earlier in this paper, cannot offer this type of insights. Our findings also differ from those in Chutani and Sethi (2018) who used a differential game model and assumed fixed prices. They found that, when symmetric channel members are considered, com- 
peting manufacturers always seem to lose from cooperative advertising programs to the benefit of retailers, implying that cooperative advertising cannot be implemented.

Finally, this research highlights the importance of modelling competition at both the manufacturing and retailing levels. Compared with a supply chain with competing manufacturers and a monopolistic retailer (Karray et al., 2017a), results from the special case of retail differentiation show that adding a non-competitive retailer can change channel members' interest in cooperative advertising programs. In addition, retail competition, even when very low, makes cooperative advertising programs attractive for manufacturers as it stimulates retailer advertising, positively affects demand, and allows manufacturers to charge higher wholesale prices. The effect of modelling retail competition is more drastic for retailers than it is for manufacturers. Contrary to a monopolistic retail channel setting, competing retailers do not benefit from cooperative advertising, in most cases. Also, while manufacturers' and their monopolistic retailer's preferences are aligned in most cases, accounting for retail competition can make the interests of these channel members almost irreconcilable. Manufacturers have no choice but to encourage retailers to invest in local advertising, which also contributes to LT sales. Our findings from the special case of product differentiation show that cooperative advertising agreements offered by manufacturers of differentiated products to competing retailers always benefit the manufacturers but not the retailers. This result differs from previous research that modelled the LT effects of retail advertising in a one manufacturer, two-retailer supply chain (Huang et al., 2018), mainly because we solve for prices in our modelling approach.

Future research can extend our work in many ways. For example, while cooperative advertising can stimulate retail demand, it also can impact its inventory planning and related costs (De Giovanni et al., 2019). Such considerations can also impact consumers' preferences (e.g., stockouts). Other promotional and advertising efforts (e.g., manufacturers' and retailers' national brand advertising) can also be taken into account to further understand how these decisions interact to influence consumers' preferences for products and supply chain profits. Also, alternative formulations can model retailers' digital campaigns which may require a more continuous advertising effort. Finally, the role of media agencies can also be explored in competitive supply chain settings (Gou et al., 2020).

\section{References}

Ataman, M. B., Van Heerde, H. J., \& Mela, C. F. (2010). The Long-Term Effect of Marketing Strategy on Brand Sales. Journal of Marketing Research 47(5), 866-882.

Aust, G., \& Buscher, U. (2014a). Cooperative advertising models in supply chain management: A review. European Journal of Operational Research, 234, 1-14.

Aust, G., \& Buscher, U. (2014b). Vertical cooperative advertising in a retailer duopoly. Computers 83 Industrial Engineering, 72, 247-254.

Barkholz, D. (2015). September 10. Toyota tells dealers that below-invoice ads are taboo. Automotive News. Retrieved from https://www.autonews.com/article/20150910/RETAIL07/150919980/toyota-tellsdealers-that-below-invoice-ads-are-taboo

Bergen, M., \& John, G. (1997). Understanding cooperative advertising participation rates in conventional channels. Journal of Marketing Research 34(3), 357-69.

Borrell Associates. (2015). The changing face of co-op programs. Retrieved from https://www.netsertive.com/netsertivereports/ 
Buil, I., de Chernatony, L., \& Martínez, E. (2013). Examining the role of advertising and sales promotions in brand equity creation. Journal of Business Research 66(1), $115-122$.

Choi, C. S., \& Coughlan, A. T. (2006). Private label positioning: Quality versus feature differentiation from the national brand. Journal of Retailing 82, 79-93.

Chutani, A., \& Sethi, S. P. (2012). Optimal advertising and pricing in a dynamic durable goods supply chain. Journal of Optimization Theory and Applications 154(2), 615-643.

Chutani, A., \& Sethi, S. P. (2014). A feedback Stackelberg game of cooperative advertising in a durable goods oligopoly. In J. L. Haunschmied, S. Wrzaczek, \& V. Veliov (Eds.), Dynamic games in economics (pp. 89-114). Germany: Springer.

Chutani, A., \& Sethi, S. P. (2018). Dynamic cooperative advertising under manufacturer and retailer level competition. European Journal of Operational Research 268, 635-652.

De Giovanni, P., Karray, S., \& Martín-Herrán, G. (2019). Vendor management inventory with consignment contracts and the benefits of cooperative advertising. European Journal of Operational Research 272(2), 465-480.

DelVecchio, D., Henard, D. H., \& Freling, T. H. (2006). The effect of sales promotion on post-promotion brand preference: A meta-analysis. Journal of Retailing 82(3), 203213.

Freimer, M., \& Horsky, D. (2012). Periodic advertising pulsing in a competitive market. Marketing Science 31(4), 637.

Gou, Q., Shao, J., Wang, X., \& Yu, L. (2020). Co-op supply chains with a local media company: Models and analysis. Transportation Research Part E: Logistics and Transportation Review 136, 101893.

Guyt, J. Y., \& Gijsbrechts, E. (2020). Evaluating the Effectiveness of Retailer-Themed Super Saver Events. Journal of Marketing 84(2), 92-113.

Häckner, J, (2000). A note on price and quantity competition in differentiated oligopolies. Journal of Economic Theory 93(2), 233-239.

He, X., Krishnamoorthy, A., Prasad, A., \& Sethi, S. P. (2011). Retail competition and cooperative advertising. Operations Research Letters 39, 11-16.

Herrington, J. D., \& Dempsey, W. A. (2005). Comparing the current effects and carryover of national-, regional-, and local-sponsor advertising. Journal of Advertising Research 45(1), 60-72.

Huang, Z., Nie, J., \& Zhang, J. (2018). Dynamic cooperative promotion models with competing retailers and negative promotional effects on brand image. Computers 86 Industrial Engineering 118, 291-308.

Jørgensen, S., Sigué, S. P., \& Zaccour, G. (2000). Dynamic cooperative advertising in a marketing channel. Journal of Retailing 76, 71-92.

Jørgensen, S., Sigué, S. P., \& Zaccour, G. (2001). Stackelberg leadership in a marketing channel. International Game Theory Review 3(1), 1-14.

Jørgensen, S., Taboubi, S., \& Zaccour, G. (2003). Retail promotions with negative brand image effects: Is cooperation possible? European Journal of Operational Research 150, 395-405. 
Jørgensen, S., \& Zaccour, G. (2014). A survey of game-theoretic models of cooperative advertising. European Journal of Operational Research 237, 1-14.

Karray, S. (2015). Cooperative promotions in the distribution channel. OmegaInternational Journal of Management Science 51, 49-58.

Karray, S., \& Amin, S. H. (2015). Cooperative advertising in a supply chain with retail competition. International Journal of Production Research 53(1), 88-105.

Karray, S., Martín-Herrán, G., \& Sigué, S. P. (2017a). Cooperative advertising for competing manufacturers: The impact of long-term promotional effects. International Journal of Production Economics 184, 21-32.

Karray, S., Martín-Herrán, G., \& Zaccour, G. (2017b). Assessing the profitability of cooperative advertising programs in competing channels. International Journal of Production Economics 187, 142-158.

Karray, S., \& Zaccour, G. (2007). Effectiveness of coop advertising programs in competitive distribution channels. International Game Theory Review 9(2), 151-167.

Liu, B., Cai, G., \& Tsay, A. (2014). Advertising in asymmetric competing supply chains. Production and Operations Management 23(11), 1845-1858.

Lus, B., \& Muriel, A. (2009). Measuring the impact of increased product substitution on pricing and capacity decisions under linear demand models. Production and Operations Management 18(1), 95-113.

Martín-Herrán, G., \& Sigué, S. P. (2017a). An integrative framework of cooperative advertising: Should manufacturers continuously support retailer advertising? Journal of Business Research 70, 67-73

Martín-Herrán, G., \& Sigué, S. P. (2017b). Retailer and manufacturer advertising scheduling in a channel. Journal of Business Research 78, 93-100.

Martín-Herrán, G., Sigué, S. P., \& Zaccour, G. (2010). The dilemma of pull and pushprice promotions. Journal of Retailing 86(1), 51-68.

Mitsubishi Motors (2012). Individual co-op assistance program. Available at: http://tempe.acbcoop.com/Paranet60/ClientDocs/MitsubishiNAMultipoint/2012CoopGuidelines04-06.pdf

Mitsubishi Motors (2015). Individual co-op assistance program. Available at: http://tempe.acbcoop.com/Paranet60/ClientDocs/8998/2015CoopGuidelines0406.pdf

Samuelson, P. A., (1974). Complementarity: An essay on the 40th anniversary of the Hicks-Allen revolution in demand theory. Journal of Economics Literature 12(4), 12551289.

Sigué, S. P., \& Chintagunta, P. (2009). Advertising strategies in a franchise system. European Journal of Operational Research 198(2), 655-665.

Sigué, S. P., \& Karray, S. (2007). Price competition during and after promotions. Canadian Journal of Administrative Sciences 24(2), 80-93.

Singh, N., \& Vives, X. (1984). Price and quantity competition in a differentiated duopoly. Rand Journal of Economics 15(4), 546-554.

Spence, M. (1976). Product differentiation and welfare. American Economic Review, $66(2), 407-414$. 
Sriram, S., Balachander, S., \& Kalwani, M. U. (2007). Monitoring the dynamics of brand equity using store-level data. Journal of Marketing 71(2), 61-78.

TastyAd (2018). Top Companies that Offer Co-Op Billboard Advertising. Retrieved from TastyAd website: https://www.tastyad.com/top-companies-that-offer-coop-billboard-advertising/

Xie, J., \& Ai, S. (2006). A note on cooperative advertising, game theory and manufacture-retailer supply chains. Omega, The International Journal of Management Science 34(5), 501-504.

Yamaha co-op advertising guidelines (2016). Retrieved from Yamaha Motor Canada website: www.yamaha-motor.ca

Yan, R. (2010). Cooperative advertising, pricing and firm performance in the emarketing age. Journal of the Academy of Marketing Science 38, 510-519.

Yi, Y., \& Yoo, J. (2011). The long-term effects of sales promotions on brand attitude across monetary and non-monetary promotions. Psychology $\&$ Marketing 28(9), 879896.

Zhang, J., Gou, Q., Liang, L., \& Huang, Z. (2013). Supply chain coordination through cooperative advertising with reference price effect. Omega, The International Journal of Management Science 41, 345-353. 